\title{
Geographic Clustering of Underage Drinking and the Influence of Community Characteristics
}

\author{
Beth A. Reboussin ${ }^{1,2}$, John S. Preisser ${ }^{3}$, Eun-Young Song ${ }^{2}$, and Mark Wolfson ${ }^{2}$ \\ ${ }^{1}$ Department of Biostatistical Sciences, Wake Forest University School of Medicine, Winston-Salem, \\ NC, USA \\ ${ }^{2}$ Department of Social Sciences and Health Policy, Wake Forest University School of Medicine, \\ Winston-Salem, NC, USA \\ ${ }^{3}$ Department of Biostatistics, University of North Carolina, Chapel Hill, NC, USA
}

\section{Abstract}

The aim of this paper was to examine the extent to which underage drinking clusters geographically in a sample of communities, and to investigate the manner in which community-level contexts are related to this process. We used data from a randomized community trial of underage drinking to provide the first quantitative estimates of the magnitude of the geographic clustering of underage drinking based upon pairwise odds ratios (PWORs). The Enforcing Underage Drinking Laws Randomized Community Trial provided data from repeated cross-sectional samples of youth aged 14-20 from 68 communities surveyed in 2004, 2006, and 2007 ( $\mathrm{n}=18,730$ ). Past 30-day drinking, binge drinking, getting drunk, experiencing non-violent consequences as a result of drinking and making a purchase attempt all significantly clustered within-communities with PWORs ranging from 1.05 to 1.21 . After adjustment for individual-level characteristics, results remained relatively unchanged. However, there was evidence that the magnitude of the clustering varied as a function of neighborhood disadvantage, neighborhood disorder, and family structure. Clustering of drunkenness and experiencing non-violent consequences as a result of drinking was greatest in the least economically disadvantaged and least disordered communities with the greatest percentage of married couple families. The clustering of making a purchase attempt, however, was greatest in more disordered communities, specifically the largest communities with the highest degree of residential mobility and housing density. These findings that clustering of underage drinking behaviors varies by community context has the potential for identifying the types of communities to target for underage drinking behavior-specific preventive interventions.

\section{Keywords}

adolescent; alcohol; alternating logistic regression; community context; epidemiology; geographic clustering

(C) 2009 Elsevier Ireland Ltd. All rights reserved.

Correspondence concerning this article should be addressed to: Beth A. Reboussin, PhD, Department of Biostatistical Sciences, Wake Forest University School of Medicine, Medical Center Boulevard, Winston-Salem, NC 27157. Tel (336)-713-5213, Fax (336)-713-5308, brebouss@wfubmc.edu.

Publisher's Disclaimer: This is a PDF file of an unedited manuscript that has been accepted for publication. As a service to our customers we are providing this early version of the manuscript. The manuscript will undergo copyediting, typesetting, and review of the resulting proof before it is published in its final citable form. Please note that during the production process errors may be discovered which could affect the content, and all legal disclaimers that apply to the journal pertain. 


\section{Introduction}

Underage drinking in the United States is an increasingly relevant public health issue. Although underage drinking decreased following changes in the minimum purchase age in the mid 1980s, prevalence rates remain at relatively high levels (NRC, 2004). Alcohol is the drug of choice among 12-20 year olds, with a higher percentage of youth drinking alcohol than using tobacco or illicit drugs (SAMHSA, 2006). While less than half of youth have tried alcohol by the time they reach $8^{\text {th }}$ grade, almost two thirds have tried alcohol by $10^{\text {th }}$ grade and almost three fourths by $12^{\text {th }}$ grade (Johnston et al., 2008). Rates of hazardous or risky patterns of drinking also escalate during this developmental period. According to the 2007 Monitoring the Future study, the percentage of youth getting drunk at least once in the past month increases from $6 \%$ among $8^{\text {th }}$ graders to $18 \%$ among $10^{\text {th }}$ graders with almost a third of youth reporting getting drunk in the past month by $12^{\text {th }}$ grade (Johnston et al., 2008). Heavy episodic or binge drinking (having five or more drinks in a row) also increases dramatically during adolescence with $10 \%$ of $8^{\text {th }}$ graders reporting heavy episodic or binge drinking compared to $22 \%$ of $10^{\text {th }}$ graders and $26 \%$ of $12^{\text {th }}$ graders.

Adolescents face widespread individual and social consequences as a result of their drinking, which may negatively impact their successful transition from adolescence to adulthood.

Alcohol use in adolescence is associated with the four leading causes of death within this age group: motor-vehicle crashes, other unintentional injuries, homicide and suicide; (CDC,

2004). Numerous studies have found that adolescent drinkers are at increased risk of engaging in violent and aggressive behaviors (DuRant et al., 1997; Grunbaum et al., 1998; White et al., 1999; Swahn et al., 2004), increased sexual activity and unsafe sexual practices (Graves and Leigh, 1995; Leigh et al., 1995; Duncan et al., 1999; Cooper, 2002) and sexual victimization (Kreiter et al., 1999; Champion et al., 2004). Adolescent alcohol use may also have deleterious effects on psycho-social development. Early onset drinking is a risk factor for progression to illicit drug use (Kandel and Yamaguchi, 1993; Wagner and Anthony, 2002; Ellickson et al., 2003), as well as an increased risk in young adulthood of alcohol abuse and dependence (Robins and Przybeck, 1985; Anthony and Petronis, 1995; Grant et al., 2001). Moreover, alcohol use at an early age may have long-lasting effects on intellectual capabilities (Brown et al., 2000) and may impede one's ability to attain educational and occupational goals (Kandel and Yamaguchi, 1987; Braun et al., 2000).

Despite the proliferation of efforts over the past 10-15 years to change the community-wide environment surrounding underage drinking (Hingson et al., 1996; Perry et al., 1996; Grube, 1997; Wagenaar et al., 2000), there is limited data on the degree to which underage drinking clusters in communities. For the purposes of this paper, "clustering" refers to the tendency of the drinking behaviors of individuals within the same geographic area to be more alike than that of others from different geographical areas. In most studies, clustering of outcomes is treated as a 'design effect' that must be accounted for in order to estimate variances correctly. However, clustering itself can have important substantive implications in epidemiologic research. It can provide insights into disease transmission, etiology and risk factors operating within geographic areas that might account for the higher or lower prevalence of disease. For example, in a recent study, Christakis and Fowler (2007) found that obesity clustered within social networks and was not attributable to the selective formation of social ties among obese persons but rather the spread of negative health behaviors. This finding highlighted the need to approach obesity as a public health problem and to design interventions focused on spreading positive health behaviors through social networks. Investigators studying the epidemiology of drug use have also recognized its geographic clustering. In the early 1970s, researchers cited evidence of clustering of opiate and heroin use in communities (Hughes et al., 1971; Greene and Dupont, 1974). The identification of this clustering allowed for the implementation of intensive outreach and treatment programs in targeted communities. Clustering was also shown 
to contribute to the cocaine and crack-cocaine epidemics of the late 1980s and early 1990s (e.g. Dunlap and Johnson, 1992). More recently, researchers have demonstrated that cocaine use (Petronis and Anthony, 2000, 2003) and marijuana use (Bobashev and Anthony, 2000) clusters within US neighborhoods and cities while others have found evidence of clustering of inhalant use in Panama (Delva et al., 2000) and marijuana use in New Zealand (Wells et al., 2008).

Considerable research has demonstrated associations between characteristics of communities and adolescent problems, such as delinquent behavior, criminal activity, teen parenthood, and early school leaving (see Leventhal and Brooks-Gunn, 2000 for a comprehensive review). However, the community environment has been relatively understudied in the context of adolescent substance use, and findings are mixed. For example, Brook and colleagues (1989) found that adolescents from less sociallly cohesive neighborhoods reported more drug involvement than adolescents from more cohesive neighborhoods. More recently, Wilson et al. (2005) found that perceptions of neighborhood disorder were associated with adolescent alcohol use. Similarly, Crum et al. (1996) found that neighborhood disadvantage was associated with an increased opportunity to use cocaine, tobacco and alcohol. Duncan and colleagues (2002) reported that more stores sold alcohol in higher poverty neighborhoods, thereby increasing opportunities to use alcohol. Karvonen and Rimpela (1997) found that prolonged area unemployment was associated with an increased risk of developing a heavy drinking pattern among boys. In contrast, Ennett and colleagues (1997) found that population density and high residential mobility were associated with less cigarette and alcohol use, respectively, among elementary students. More recently, Trim and Chassin (2008) found that higher neighborhood socioeconomic status (SES) was associated with increased rates of alcohol use and consequences among a subgroup of children who were not children of alcoholics. Similarly, Chuang and colleagues (2005) reported that living in a high SES neighborhood was associated with increased risk of adolescent cigarette and alcohol use. Our research group found that while higher employment rates were associated with a decreased risk of underage drinking, higher median household income was associated with an increased risk (Song et al., in press). However, in the study by Allison and colleagues (1999), no association was found between neighborhood factors and adolescent drug and alcohol use.

Whereas the aforementioned studies examined whether geographically defined contexts (e.g., neighborhood disadvantage) were associated with an increased risk of substance use, in this paper we examine whether community-level characteristics are related to the geographic clustering of substance use. In particular, we address three research questions. First, does underage drinking cluster geographically? Because research suggests that individuals from the same socioeconomic status tend to cluster their residences in like neighborhoods (Jencks and Mayer, 1990; Coulton et al., 1996), it will be important to examine whether any observed clustering can be explained by the characteristics of the individuals who live in the community. Hence, our second research question will determine whether clustering is an artifact of the composition of the community. Finally, we will examine whether the magnitude of the clustering is associated with community-level characteristics (e.g., neighborhood disadvantage) after adjustment for individual-level characteristics. This may provide evidence as to whether community-level factors, such as neighborhood disadvantage, add collective or environmental disadvantage to the individual disadvantage of residents (Massey, 1996; Wilson, 1996). In particular, we will examine whether neighborhood SES impacts underage drinking over and above the impact of personal socioeconomic characteristics that may limit residential options (Coulton et al., 2007).

We will use data from a randomized community trial of underage drinking to provide the first quantitative estimates of the magnitude of the geographic clustering of underage drinking. Estimates will be obtained by applying the alternating logistic regression (ALR) approach used by others to estimate the geographic clustering of cocaine, marijuana and inhalant use in 
neighborhoods and cities (Bobashev and Anthony, 2000; Delva et al., 2000; Petronis and Anthony, 2000, 2003). ALR is a statistical method that uses pairwise odds ratios (PWOR) to estimate the association between binary responses from individuals residing in the same geographical area and for modeling the influence of geographic characteristics on the magnitude of this clustering (Carey et al., 1993). ALR is an innovative approach that has only recently been applied to drug use and has not been applied to the study of underage drinking. It allows flexible modeling of the pattern of clustering (PWOR model) while simultaneously modeling the marginal probability of response (mean model). Modeling the pattern of clustering with and without covariate adjustment in the mean model can help identify individual-level risk factors that might mitigate or explain the magnitude of clustering while the separate model for the PWORs can be used to estimate the level of clustering as a function of cluster-level characteristics (e.g. neighborhood disadvantage). Both of these aspects of ALR can help target prevention and intervention strategies based on individual and environmental risk factors.

\section{Methods}

\subsection{Population and Sample}

The Enforcing Underage Drinking Laws (EUDL) Program is a national initiative, funded by the United States Office of Juvenile Justice and Delinquency Prevention (OJJDP), intended to increase enforcement of underage drinking laws and reduce underage drinking. Each year since 1998, each of the 50 states was awarded a block grant to support and enhance state and local efforts to prohibit the sale and consumption of alcoholic beverages to and by minors. In addition, each year since the program began discretionary grants were awarded on a competitive basis to a subset of the states to expand the number of communities taking a comprehensive approach to prevention of underage drinking. States were free to establish criteria for deciding which communities would receive funding in their state under the discretionary grant program. The national evaluation, also funded by OJJDP, was designed to compare a sample of communities from states receiving discretionary grants with matched comparison communities not receiving such intense interventions.

The Enforcing Underage Drinking Laws Randomized Community Trial (EUDL-CT) was funded under the FY 2003 appropriation. States responding to a solicitation for the EUDL-CT were required to provide a list of 14 to 28 cities/towns that were interested in, and eligible for, participation in the EUDL-CT should the state be funded. Eligibility requirements included: (1) being an incorporated city or town with population between 25,000 and 200,000, and (2) not having engaged in high levels of certain programmatic activities to reduce underage drinking in the two years preceding the date of the solicitation (OJJDP, 2003). Based on their proposals, 5 states were funded to participate in the EUDL CT: California, Connecticut, Florida, Missouri, and New York (Wolfson et al, 2005). Using Mahalanobis's Distance (D'Agostino, 1998), communities within each state were matched based on population, median family income, and the percentages of the population that were Black, Hispanic, spoke Spanish, and were currently in college. Following creation of pairs, a random number generator was employed to assign communities to either the intervention or comparison condition. This process resulted in good balance on a variety of community-level characteristics (Wolfson et al., 2005). Thirty-four intervention communities were funded to participate in the EUDL-CT and matched to 34 comparison communities.

Date used in the analyses presented below are from a repeated cross-sectional telephone survey of 14-20 year olds conducted in 2004, 2006 and 2007 as part of the national evaluation of the EUDL-CT. The survey included questions on underage alcohol use and consequences, perceived availability of alcohol to youth, and sources of alcohol. The target sample size for each repeated cross-section was 100 youth per community in 68 communities (34 intervention 
and 34 matched comparison communities). In selecting the sample, an age-targeted list sample was drawn in each of the intervention and comparison communities. The survey sample for each community was randomly selected from a sample of telephone numbers provided by two commercial firms. When a household was contacted, the informant was asked if there was anyone living in the household who was aged 14-20. If no one in the targeted age range lived at that number, the household was classified as ineligible. If more than one person age 14-20 lived in the household, a respondent was randomly selected using the next birthday method of respondent selection. All protocols for the study were approved by the Wake Forest University School of Medicine Institutional Review Board and verbal informed consent was obtained by the interviewers prior to proceeding with the survey. The survey took an average of 20 minutes to complete and participants were not compensated. A total of 18,730 youths from 68 communities from five states in the US completed (or partially completed) the telephone survey. Starting in 2004, 6958 youth ages 14-20 completed the survey, reaching the target of 100 interviews or more in $75 \%$ of the 68 study communities. The remaining communities had between 65-95 participants. The second and third repeated cross-sectional samples in the same 68 communities resulted in sample sizes of 6133 and 5639, reaching the target of 100 interviews or more in $50 \%$ and $30 \%$ of the communities respectively in 2006 and 2007. The remaining communities had between 30-97 participants. The response rates for the survey were $48 \%$, $41 \%$ and 34\%, respectively in 2004, 2006 and 2007.

\subsection{Measures}

The geographic clustering of underage drinking in the EUDL-CT communities will be examined based on yes/no responses constructed from the following survey questions:

(1) Current drinker. "When was the last time you drank any alcohol?" A response of "Sometime in the last 7 days" or "Sometime in the last 30 days" classified an adolescent as a current drinker. Alcohol included any beer, wine coolers, wine, liquor, and mixed drinks. Drinking alcohol meant drinking more than a single sip at any one occasion.

(2) Heavy episodic or binge drinking. "Think back over the last two weeks. How many times have you had five or more drinks in a row? A drink is a glass of wine, a bottle of beer, a shot glass of liquor, a mixed drink or wine cooler." Respondents who reported binge drinking one or more times in the past two weeks were contrasted with respondents who did not report binge drinking in the past two weeks.

(3) Drunkenness. "Over the past 12 months, on how many days have you gotten drunk or "very, very high" on alcohol? Would you say ... every day or almost every day, 3 to 5 days a week, 1 or 2 days a week, 2 or 3 days a month, once a month or less, 1 or 2 days in the past 12 months, never." Respondents who reported getting drunk at least once a month were contrasted with all others.

(4) Non-violent consequences. Respondents were asked "Have you had any of the following experiences after you had been drinking?" These included being cited or arrested for drinking, possessing, or trying to buy alcohol; being cited or arrested for driving under the influence of alcohol; missing any school due to drinking; being warned by a friend about your drinking; passing out; being unable to remember what happened while drinking; breaking or damaging something; having a headache or hangover; being punished by a parent or guardian; having sex without using a condom; and being involved in a motor vehicle crash. Respondents who reported at least one of these consequences during the past year were contrasted with all others.

(5) Purchase Attempt. "In the last 30 days, how many times did you try to buy alcohol from a bar, restaurant, or store (whether you were successful or not)?" Respondents who reported attempting to purchase alcohol at least once during the past month were contrasted to all others. 
If communities differ in terms of their composition with respect to factors associated with underage drinking, it is possible that our estimates of geographical clustering could be artifacts of these differences. For this reason, several individual-level characteristics of the participants, some of which most certainly mark varying levels of vulnerability, predisposition, or risk of underage drinking were incorporated into the models in an effort to examine whether their statistical adjustment might attenuate the estimates of geographical clustering. We concentrated our analyses on the well-measured socio-demographic characteristics of age, gender, race, and family structure found in our previous studies to be associated with underage drinking (Reboussin et al., 2005; Song et al., 2009). Age measured in years was categorized as 14-15, 16-18, and 19-20 year olds. Race compared Whites and non-Whites (including Hispanics). Family structure was measured by responses to two questions (living with mother or female guardian and living with father or male guardian) and grouped as living with mother/ female guardian and father/male guardian compared to living with mother/female guardian only or father/male guardian only. Hence, this variable compares youth living in a singleparent/guardian household to those living in a two-parent/guardian household. We also included mother's educational attainment, in particular having a college-degree, as a measure of socio-economic status due to recent focused interest in this reasonably well-measured characteristic (Crum et al., 2005, 2006).

In the analyses presented below, we examine whether the magnitude of the clustering of underage drinking depends on community-level environmental contexts. We defined "community" in this study as the city or town participating in the EUDL Community Trial (EUDL-CT). Based on prior work by our research group and others on the association between community characteristics and substance use (Allison et al., 1999; Duncan et al., 2002; Chuang et al., 2005; Song et al., 2009), we consider four groups of community-level characteristics: (1) neighborhood disadvantage, (2) neighborhood disorder, (3) family structure and (4) racial composition. The specific variables comprising these four groups and their definitions are listed in Table 1. Data was obtained from the 2000 U.S. Census Summary Files 1 and 3 using American Factfinder at http://factfinder.census.gov. Census data were extracted for all 68 communities. The 2000 US Census and Youth survey data were merged using city and state Federal Information Processing Standards (FIPS) codes. Crime data were obtained from the 2003 Federal Bureau of Investigation (FBI) Uniform Crime Reports Table 8 available at http://www.fbi.gov/ucr/03cius.htm. All community-level characteristics were divided into quartiles based on percentiles of the distribution of the 68 study communities.

\subsection{Statistical Analyses}

The clustering of past 30-day drinking, heavy episodic or binge drinking, drunkenness, nonviolent consequences as a result of drinking and making a purchase attempt was estimated within-communities using the alternating logistic regression (ALR) method developed by Carey and colleagues (1993) and implemented by other researchers (e.g. Katz et al., 1993; Bobashev and Anthony, 2000; Delva et al., 2000; Petronis and Anthony, 2000, 2003; Preisser et al., 2003; Wells et al., 2008). Pairwise odds ratios (PWOR) estimated from ALR yield an interpretable statistical index that reflects how strongly underage drinking occurs in clusters (e.g. within-communities). If we take the outcome of past 30-day drinking, for example, we can estimate a within-community PWOR that is interpreted as the odds of past 30-day drinking for a youth given that another randomly chosen youth residing in the same community is a past 30-day drinker relative to the odds if that randomly chosen youth is not a past 30-day drinker. In other words, these odds ratios represent the excess odds of reporting underage drinking for a youth in a community where another randomly selected youth from the same community also reports underage drinking relative to the odds if the randomly selected youth does not report underage drinking. 
We began by estimating the observed within-community clustering for each outcome in a model without adjusting for individual-level covariates. In this case, the PWOR can be calculated from a $2 \times 2$ table containing all possible pairs of youth from the same community as shown in Table 2 (Katz et al., 1993). The cells of the table refer to pairs of youth with respect to the outcome of interest. Pairs of youth concordant on the outcome are counted in cells a and c. Since we do not distinguish between youth, the number of discordant pairs (outcome 'yes' for exactly one youth) is evenly divided in the table. The PWOR is calculated like an ordinary odds ratio $\mathrm{PWOR}=\mathrm{a} \times \mathrm{c} /(\mathrm{b} / 2)^{2}$ where $\mathrm{a}$ is the number of pairs with both youth reporting yes, $\mathrm{c}$ is the number of pairs with both youth reporting no, and $\mathrm{b}$ is the number of pairs with exactly one youth reporting yes. Consistent with odds ratios from logistic regression analysis, the PWOR takes a value of 1.0 when there is no clustering of the outcome of interest. If the PWOR is greater than 1.0 then the past 30-day drinking of one youth is statistically dependent upon the past 30-day drinking of another randomly chosen youth residing in the same community, over and above the expectation based upon randomly paired selections of youth without respect to communities.

We then conducted an alternating logistic regression for each outcome that estimated the PWORs while simultaneously modeling the outcome (e.g. past 30-day drinking) as a function of individual-level covariates. In particular, we simultaneously adjusted for an individual's age, gender, race, mother's education and family structure in these models. The model, referred to as the mean model, is given by

$$
\operatorname{Logit} \mathrm{P}\left(\mathrm{Y}_{\mathrm{ij}}=1\right)=\beta_{0}+\Sigma \beta_{1} \mathrm{X}_{1}
$$

where $\mathrm{Y}_{\mathrm{ij}}$ takes a value of 1 if youth $j$ in community $i$ is a past 30-day drinker and 0 else and $\mathrm{X}_{\mathrm{j} 1}$ are individual-level covariates / associated with past 30 -day drinking. The parameter $\beta_{1}$ is the $\log$ odds ratio for the odds of past 30-day drinking associated with the $l^{\text {th }}$ individual-level covariate. ALR alternates between two steps: (1) estimation of the logistic regression parameters for the individual-level covariates in the mean model via a set of first-order generalized estimating equations, and (2) an offset logistic regression for estimation of the PWORs (see Carey et al., 1993 for estimation details). The inclusion of covariates in the mean model in (1) that describe youth and are associated with past 30-day drinking will increase or decrease the PWOR depending on the direction of the correlation of the covariate within communities (Katz et al., 1993). The impact of adding covariates will be gauged by comparing the adjusted and unadjusted PWORs. The model in (1) can be interpreted as adjusting the PWOR for the composition of communities with respect to the individual-level covariates (Petronis and Anthony, 2003).

To address the question of whether underage drinking clusters within communities as a function of community-level characteristics, we then modeled the PWOR using a log odds ratio regression model given by

$$
\log \operatorname{PWOR}\left(\mathrm{Y}_{\mathrm{ijk}}, \mathrm{Y}_{\mathrm{ilm}}\right)=\alpha_{0}+\sum \alpha_{\mathrm{k}} \mathrm{Z}_{\mathrm{ijklm}}, \mathrm{j} \neq 1
$$

where $\mathrm{Y}_{\mathrm{ijk}}=1$ if the $j^{\text {th }}$ youth in the $i^{\text {th }}$ community of type $k$ reports past 30-day drinking, $\mathrm{Y}_{\mathrm{ilm}}$ is the corresponding response for the $l^{\text {th }}$ youth in the $i^{\text {th }}$ community of type $m$ and $\mathrm{Z}_{\mathrm{ijklm}}$ $=1$ if $k=m$ (that is, youth $j$ and $l$ reside in the same community of type $k$ ). If follows that exp $\left(\alpha_{0}\right)$ is the PWOR for the reference type community and $\exp \left(\alpha_{0}+\alpha_{k}\right)$ is the PWOR withincommunity of type $\mathrm{k}$. We defined community types by membership in a specific quartile representing level of neighborhood disadvantage, level of neighborhood disorder, type of family structure, and racial composition. Each community-level characteristic is considered in 
a separate PWOR model; referred to as a contextual PWOR model. As described above, the contextual PWOR model is fit simultaneously with the model in (1) which adjusts for an individual's age, gender, race, mother's education and family structure. Wald tests were computed to test the equality of the pairwise odds ratios in the contextual PWOR model. All models were fit using SAS PROC GENMOD with the LOGOR option on the REPEATED statement (Preisser et al., 2003).

\section{Results}

In our sample of 18, 730 youth from 68 communities, half were female and the majority were white (79.0\%). Approximately $36 \%$ of the youth were $14-15$ years old, $53 \%$ were $16-18$ years old, and $11 \%$ were $19-20$ years old. More than half of the youth had a mother with a college education $(57 \%)$ and $18 \%$ came from single-parent households. Almost a third of the sample reported drinking during the past 30 days and $28 \%$ reported experiencing a non-violent consequence during the past year as a result of drinking. More risky drinking patterns such as heavy episodic or binge drinking during the past two weeks and drunkenness at least once a month during the past year were reported by $11 \%$ and $24 \%$ of the sample, respectively. Approximately $6 \%$ reported making a purchase attempt at least once during the past month.

Underage drinking clusters within communities as shown by the estimated PWORs and their 95\% confidence intervals in Table 3. For each outcome, all of the PWORs are greater than unity ignoring the characteristics of the individuals living in the communities. Past 30-day drinking, binge drinking, getting drunk, experiencing non-violent consequences as a result of drinking and making a purchase attempt all significantly clustered within communities. The PWORs were approximately 1.05 for non-violent consequences as a result of drinking, 1.08 for past 30-day drinking, heavy episodic or binge drinking, and getting drunk and 1.21 for making an alcohol purchase attempt. This means, for example, that the odds that a youth makes an alcohol purchase attempt is $21 \%$ greater if a randomly selected youth from the same community makes a purchase attempt relative to the odds if that youth does not make an alcohol purchase attempt. After adjustment for individual-level characteristics, including age, gender, race, mother's education and family structure, the results remained relatively unchanged. This finding suggests that within-community clustering of underage drinking behaviors is not an artifact of the composition of communities with respect to individual-level characteristics.

The contextual PWOR model presented in (2) was then fit to the data for each communitylevel characteristic described in Table 1 to examine whether they impact the magnitude of clustering while simultaneously adjusting for individual-level characteristics of age, gender, race, mother's education and family structure in (1). The PWORs were allowed to depend on the quartile of the community-level characteristics measuring neighborhood disadvantage, neighborhood disorder, family structure and racial composition. With regard to neighborhood disadvantage (Table 4), clustering of drunkenness and non-violent consequences was greatest in communities with the highest median household income $(\mathrm{PWOR}=1.22 ; 95 \% \mathrm{CI}=1.10,1.34$ and $\mathrm{PWOR}=1.17 ; 95 \% \mathrm{CI}=1.10,1.24$, respectively), fewest households living in poverty (PWOR=1.21; 95\%CI=1.09, 1.33 and $\mathrm{PWOR}=1.13 ; 95 \% \mathrm{CI}=1.07,1.21$, respectively), and greatest percentage of college-educated individuals ( $\mathrm{PWOR}=1.15 ; 95 \% \mathrm{CI}=1.03,1.28$ and $\mathrm{PWOR}=1.11 ; 95 \% \mathrm{CI}=1.05,1.18$, respectively). Clustering was non-significant or only marginally significant for the other levels (quartiles) of neighborhood disadvantage. There was some evidence of a gradient in clustering of reported drunkenness as the percent of renters in the community decreased; the PWOR for communities with the fewest renters was 1.16 (95\% $\mathrm{CI}=1.07,1.25)$ and the PWOR for communities with the greatest percentage of renters was $1.03(95 \% \mathrm{CI}=1.01,1.06)$. Clustering of past 30 -day drinking increased with the percentage of the community that was college educated $(\mathrm{PWOR}=1.21 ; 95 \% \mathrm{CI}=1.07,1.36$ for the most college educated and $\mathrm{PWOR}=1.02 ; 95 \% \mathrm{CI}=1.00,1.04$ for the least percentage of college 
educated individuals) but was not associated with other indicators of neighborhood disadvantage. Both clustering of heavy episodic or binge drinking and making an alcohol purchase attempt were not associated with levels of neighborhood disadvantage.

There was also evidence that the magnitude of the clustering of drunkenness and non-violent consequences was related to the level of neighborhood disorder as seen in Table 5. Clustering of reported drunkenness and non-violent consequences was greatest in communities with the least crime ( $\mathrm{PWOR}=1.26 ; 95 \% \mathrm{CI}=1.12,1.43$ and $\mathrm{PWOR}=1.16 ; 95 \% \mathrm{CI}=1.07,1.25$, respectively), the smallest population size $(\mathrm{PWOR}=1.19 ; 95 \% \mathrm{Ci}=1.03,1.36$ and $\mathrm{PWOR}=1.12$; $95 \% \mathrm{CI}=1.04,1.20$, respectively), and the lowest level of housing density ( $\mathrm{PWOR}=1.18 ; 95 \%$ $\mathrm{CI}=1.07,1.30$ and $\mathrm{PWOR}=1.11 ; 95 \% \mathrm{CI}=1.04,1.18$, respectively). It clustered to a much lesser extent and was sometimes non-significant for the other quartiles. Communities in the lowest two quartiles of residential mobility had the greatest degree of clustering of drunkenness and non-violent consequences. Clustering of non-violent consequences also increased as the percentage of vacant housing units decreased (PWOR=1.09; 95\% CI=1.04, 1.15 for the least vacant and $\mathrm{PWOR}=1.02 ; 95 \% \mathrm{CI}=1.00,1.04$ for the greatest percentage of vacant houses). Clustering of past 30 day drinking was greatest in communities with the least amount of crime (PWOR $=1.19 ; 95 \% \mathrm{CI}=1.05,1.34$ ) and smallest in communities with the most crime ( $\mathrm{PWOR}=1.03 ; 95 \% \mathrm{CI}=0.99,1.07)$. Making an alcohol purchase attempt had an interesting relationship with neighborhood disorder in contrast to drinking behaviors and consequences. Clustering of alcohol purchase attempts was greatest in communities with the largest population size $(\mathrm{PWOR}=1.46 ; 95 \% \mathrm{CI}=1.15,1.85)$ and communities with the lowest and highest degree of housing density (PWOR=1.36; 95\% CI=1.14, 1.62 and $\mathrm{PWOR}=1.39 ; 95 \%$ $\mathrm{CI}=1.03,1.88$, respectively). Although only marginally significant, clustering of alcohol purchase attempts was also greatest in communities with the highest levels of residential mobility (PWOR=1.54; 95\% CI=1.25, 1.91 for the highest quartile).

Table 6 shows that communities with the fewest households with grandparents as caregivers evidenced the greatest amount of clustering of heavy episodic or binge drinking ( $\mathrm{PWOR}=1.15$; $95 \% \mathrm{CI}=1.05,1.25)$, drunkenness $(\mathrm{PWOR}=1.24 ; 95 \% \mathrm{CI}=1.10,1.40)$ and non-violent consequences ( $\mathrm{PWOR}=1.16 ; 95 \% \mathrm{CI}=1.08,1.25)$. Communities with the fewest female headed households and greatest married couple families had the greatest clustering of drunkenness ( $\mathrm{PWOR}=1.20 ; 95 \% \mathrm{CI}=1.09,1.33$ and $\mathrm{PWOR}=1.18 ; 95 \% \mathrm{CI}=1.08,1.30$, respectively) and nonviolent consequences $(\mathrm{PWOR}=1.13 ; 95 \% \mathrm{CI}=1.06,1.20$ and $\mathrm{PWOR}=1.12 ; 95 \% \mathrm{CI}=1.05,1.18$, respectively). Clustering of alcohol purchase attempts was not significantly associated with indicators of family structure but was greatest in communities with the lowest percentage of foreign born individuals as shown in Table 9 (PWOR=1.71; 95\% CI=1.44, 2.03). There was no association between clustering of past 30 day drinking, family structure and racial composition.

\section{Discussion}

This study provides the first quantitative estimates of the magnitude of the geographic clustering of underage drinking based on pairwise odds ratios. Using data from a randomized community trial of underage drinking in 68 US communities, we found evidence for geographic clustering of underage drinking within these communities. Underage drinking and experiencing non-violent consequences as a result of drinking co-occur within communities approximately $10 \%$ more often than one would expect if these behaviors were distributed randomly across communities. Making an alcohol purchase attempt co-occurs 20-30\% more often. After adjustment for an individual's age, gender, race, mother's education and family structure, the results remained relatively unchanged and retained statistical significance. This suggests that within-community clustering of underage drinking behaviors is not an artifact of the composition of communities with respect to individual-level characteristics. Instead, there 
is some evidence that the geographic clustering of underage drinking behaviors is associated with community-level characteristics. Clustering of getting drunk and experiencing nonviolent consequences as a result of drinking was greatest in the least disadvantaged and disordered communities, with these behaviors co-occurring as much as 20-30\% more often. In fact, these behaviors generally did not co-occur in more disadvantaged and disordered communities more than expected by chance.

The finding that underage drinking and its consequences clusters in communities with greater socioeconomic advantage and less disorder is consistent with some previous studies which found an association between living in an economically advantaged community and risk of underage drinking (Ennett et al., 1997; Chuang et al., 2005; Trim and Chassin, 2008; Song et al., 2009). It is important to recognize, however, that the community-level characteristics that we considered such as neighborhood disadvantage and disorder represent structural characteristics of communities which can be measured objectively by administrative data, or in our case, the census. The question remains as to how community structure collectively influences the adolescents living in these communities over and above the individual-level risk factors that predispose them to underage drinking.

Research on the geographic concentration of adolescent problems, and in particular substance use, has focused on the stressors of living in disadvantaged neighborhoods and the lack of social cohesion in these neighborhoods, which result in failure to monitor and control youth activities (Duncan et al., 2002). There has been little consideration of the experience of youth residing in more affluent and suburban neighborhoods. However, in two studies by Luthar and colleagues, affluent, suburban youth were found to report significantly higher levels of substance use compared to national normative samples (Luthar and D'Avanzo, 1999; Luthar and Becker, 2002). One potential explanation put forward by Luthar and colleagues for these increased risks are the academic and extracurricular achievement pressures that exist in more advantaged communities. Both parental pressure to achieve and a child's own perfectionism have been shown to place children at risk for increased substance use (Steinhausen and Metzke, 1998). Therefore, in more socioeconomically advantaged communities youth may experience different types of stressors than youth in disadvantaged communities, specifically achievement pressures, which predispose them to drink alcohol. Alternatively, Chuang et al. (2005) found that high SES neighborhoods showed higher rates of parental drinking, which was in turn associated with adolescent alcohol use. Therefore, youth living in high SES communities may have higher levels of exposure to parental drinking (either their own or their friends' parents) and more favorable norms and attitudes towards drinking. In addition, sociologists have demonstrated that junior high school students from upper middle-class families often have little or no after-school supervision by adults (Hochschild, 1997). Both inadequate parental monitoring (Chilcoat and Anthony, 1996; Kandel and Davies, 1996) and lack of supervision after school (Richardson et al., 1993; Mulhall et al., 1996) have been shown to be associated with increased substance use. Both of these factors may increase opportunities for youth within the community to use alcohol unsupervised, either at home or at a friend's home. In fact, in the current study, we found an increased clustering of drinking in communities with more married couple families and fewer grandparents as caregivers. This may suggest less supervision in married couple families with two-career households and greater supervision when grandparents are the caregivers supporting the findings of Hochschild (1997).

It was also notable that the magnitude of the clustering of less risky drinking, in particular, past 30-day drinking, did not depend on as many community-level indicators as more risky drinking like drunkenness. This may reflect the possibility that more risky drinking is not only influenced by a broader group of community-level factors but is also more likely to occur in community environments such as parties or other group gatherings. In turn, these types of community environments might be influenced to a greater extent by parental monitoring and attitudes 
towards drinking; the practices of alcohol outlets, and local law enforcement practices, which may vary considerably across communities (Montgomery et al., 2006). Also of note was the lack of association between any community-level factors and clustering of binge drinking, another risky drinking behavior. While binge drinking was not as prevalent in our sample compared to getting drunk ( $11 \%$ versus $24 \%$ ), in a study of college students, O'Brien and colleagues (2006) found that getting drunk was a better indicator of risk for experiencing an injury as a result of drinking than was binge drinking. It is also possible that our measure of getting drunk which indicates getting drunk at least once a month over the past year may reflect a more regular drinking pattern that may be influenced by a stable characteristic of the environment than binge drinking which could reflect a single incident of drinking over the past two weeks. The same might be said about past 30-day drinking.

The relationship between the geographic clustering of alcohol purchase attempts and community-level characteristics was an interesting one. First, we should point out that the magnitude of the clustering of alcohol purchase attempts within-communities was the greatest among the outcomes we considered but was not associated with any of our indicators of neighborhood disadvantage. It was, however, significantly associated with greater population size and housing density and marginally associated with greater residential mobility. The clustering of alcohol purchase attempts in more disordered communities or at least larger communities with a less stable population may reflect greater availability and access to alcohol as a function of the existence of more stores that sell alcohol as well as less enforcement of the purchase laws with the increased density of stores.

Limitations in our study should be noted. First, only five states were funded to participate in the EUDL-CT. Therefore, our inferences are only valid for the population of communities from which we sampled. In addition, as is typical of telephone surveys, nonwhites and lower SES individuals are underrepresented in our sample as are older adolescents (i.e. 19 and 20 year olds). Although our response rates $(48 \%, 41 \%$, and $34 \%)$ are less than ideal, they are consistent with the decline in response rates all telephone surveys have experienced in recent years; the median response rate among states that conduct the Behavioral Risk Factor Surveillance System has declined from $51.1 \%$ in 2001 to $33.4 \%$ in 2007 . Although response rates are important, and potentially have an impact on the representativeness of the findings, the more significant question is whether low response rates produce biased results. The evidence to this point seems to indicate that this is not the case. Research by Keeter and colleagues 2000, (2006) demonstrated that non-response does not introduce substantial biases into the measurement of attitudes, and in Groves (2006) review of this topic he concludes that there is little empirical support for the notion that low response rate surveys de facto produce estimates with high non-response bias.

As mentioned earlier in the discussion, our analyses relied on the 2000 Census to measure community-level characteristics. While providing measures of community structure, it did not directly measure the underlying processes through which these measures may have acted to influence underage drinking. These might have included social, cultural and physical aspects of the community as well as social and cultural characteristics of the families which comprise the communities. At a minimum, the census data are crude proxies of community-specific attributes. In addition, the geographic area that we considered was determined by the EUDLCT study communities which comprised an area defined as a city or town with population between 25,000 and 200,000. It is not clear, however, what geographic area is most relevant to underage drinking and it may be difficult to define. As Diez-Roux (1998) has discussed, an individual's neighborhood may be much broader than a geographically defined area of residence. 
The magnitude of the within-community PWORs for underage drinking estimated in this study are generally smaller than those observed by Bobashev and Anthony 1998, (2000) in a study of the clustering of marijuana use within-neighborhoods and those observed by Anthony and Petronis $(2000,2003)$ in studies of the clustering of cocaine use within-neighborhoods where PWORs ranged from 1.3-2.0. Our estimates of clustering within communities of greatest socioeconomic advantage and least disorder as well as the clustering of making a purchase attempt were more similar to those observed by Delva et al. (2000) in a study of clustering of alcohol consumption within-schools in Panama where the PWOR was 1.3. Wells et al. (2008) estimated clustering of marijuana use to be 1.5 at the 'meshblock', or neighborhood, level but no clustering at the local authority level. Our estimates of within-community clustering, however, were at the level of the city and one might expect clustering within smaller geographic regions, e.g. neighborhood to be greater in magnitude. Finally, it is important to note that the data we analyzed are based on youths' self reports of alcohol use, which may be subject to some underreporting bias (Midanik, 1982; Wagenaar et al., 1993; Gruenwald and Johnson, 2006). It is also possible that, as described by Kandel and colleagues (2006), asking adolescents questions about underage drinking at home may elicit less truthful responses than asking them in a school or research setting and therefore may have resulted in an underestimation of the clustering of underage drinking.

A significant strength of the present study is the application of an innovative statistical approach to study the clustering of underage drinking and its relationship to contextual factors. Alternating logistic regression (ALR) has only recently been applied to drug use and has not been applied to the study of underage drinking despite the large number of studies focused on the influence of communities and contextual factors. An advantage of the ALR approach over other approaches in this context is that it fits a separate model for the association (clustering) thereby permitting direct control over model specification for the PWORs. This is in contrast to other approaches such as multilevel models, where the model for the association is implicit in the model for the mean. Separate models for the clustering and the mean allow us greater flexibility and can help us to target our prevention and intervention strategies to different factors or levels (individual versus community) more accurately. Finally, our estimates of the quantitative clustering of underage drinking are based on one of the larger randomized community trials to reduce youth alcohol use and problems. Randomization of 68 communities is a significant increase in size over most community trials (cf. Holder et al., 1997; Perry et al., 1998; Wagenaar et al., 2000). Not only did this enhance the precision of our estimates, but it allowed us to simultaneously examine associations at multiple levels across a broad array of contextual factors. The findings that clustering of underage drinking varies by communitylevel context has the potential for identifying the types of communities to target for underage drinking behavior-specific preventive interventions.

\section{REFERENCES}

Allison KW, Crawford I, Leone PE, Trickett E, Perez-Febles A, Burton LM, Le Blanc R. Adolescent substance use: preliminary examinations of school and neighborhood context. Am. J. Community Psychol 1999;27:111-114. [PubMed: 10425696]

Anthony JC, Petronis KR. Early-onset drug use and risk of later drug problems. Drug Alcohol Depend 1995;40:9-15. [PubMed: 8746919]

Bobashev GV, Anthony JC. Clusters of marijuana use in the United States. Am. J. Epidemiol 1998;148:1168-1174. [PubMed: 9867262]

Bobashev GV, Anthony JC. Use of alternating logistic regression in studies of drug-use clustering. Subst. Use Misuse 2000;35:1051-1073. [PubMed: 10847222]

Braun BL, Hannan P, Wolfson M, Jones-Webb R, Sidney S. Occupational attainment, smoking, alcohol intake, and marijuana use: ethnic-gender differences in the CARDIA study. Addict. Behav 2000;25:399-414. [PubMed: 10890293] 
Brook JS, Nomura C, Cohen P. A network of influences on adolescent drug involvement: neighborhood, school, peer, and family. Genet. Soc. Gen. Psychol. Monogr 1989;115:123-145. [PubMed: 2925085]

Brown SA, Tapert SF, Granholm E, Delis DC. Neurocognitive functioning of adolescents: effects of protracted alcohol use. Alcohol Clin. Exp. Res 2000;24:164-171. [PubMed: 10698367]

Carey VJ, Zeger S, Diggle P. Modelling multivariate binary data with alternating logistic regressions. Biometrika 1993;80:517-526.

Centers for Disease Control and Prevention National Center for Injury Prevention and Control. WebBased Injury Statistics Query and Reporting System (WISQARS): available online. 2004

Champion HL, Foley KL, DuRant RH, Hensberry R, Altman D, Wolfson M. Adolescent sexual victimization, use of alcohol and other substances, and other health risk behaviors. J. Adolesc. Health 2004;35:321-328. [PubMed: 15450546]

Chilcoat HD, Anthony JC. Impact of parent monitoring on initiation of drug use through late childhood. J. Am. Acad. Child Adolesc. Psychiatry 1996;35:91-100. [PubMed: 8567618]

Christakis NA, Fowler JH. The spread of obesity in a large social network over 32 years. New England Journal of Medicine 2007;357:370-379. [PubMed: 17652652]

Chuang YC, Ennett ST, Bauman KE, Foshee VA. Neighborhood influences on adolescent cigarette and alcohol use: mediating effects through parent and peer behaviors. J. Health Soc. Behav 2005;46:187204. [PubMed: 16028457]

Cooper ML. Alcohol use and risky sexual behavior among college students and youth: Evaluating the evidence. Journal of Studies on Alcohol 2002:101-117.

Coulton CJ, Chow J, Wang EC, Su MS. Geographic concentration of affluence and poverty in 100 metropolitan areas, 1990. Urban affairs review 1996;32:186-216.

Coulton CJ, Crampton DS, Irwin M, Spilsbury JC, Korbin JE. How neighborhoods influence child maltreatment: a review of the literature and alternative pathways. Child Abuse Negl 2007;31:11171142. [PubMed: 18023868]

Crum RM, Lillie-Blanton M, Anthony JC. Neighborhood environment and opportunity to use cocaine and other drugs in late childhood and early adolescence. Drug and Alcohol Dependence 1996;43:155161. [PubMed: 9023071]

Crum RM, Storr CL, Anthony JC. Are educational aspirations associated with the risk of alcohol use and alcohol use-related problems among adolescents? Substance Use and Misuse 2005;40:151-169. [PubMed: 15770882]

Crum RM, Juon HS, Green KM, Robertson J, Fothergill K, Ensminger M. Educational achievement and early school behavior as predictors of alcohol-use disorders: 35-year follow-up of the Woodlawn Study. Journal of Studies on Alcohol 2006;67:75-85. [PubMed: 16536131]

D'Agostino RB. Propensity score methods for bias reduction in the comparison of a treatment to a nonrandomized control group. Statistics in Medicine 1998;17:2265-2281. [PubMed: 9802183]

Delva J, Bobashev G, Gonzalez G, Cedeno M, Anthony JC. Clusters of drug involvement in Panama: results from Panama's 1996 National Youth Survey. Drug and Alcohol Dependence 2000;60:251257. [PubMed: 11053759]

Diez-Roux AV. Bringing context back into epidemiology: variables and fallacies in multilevel analysis. American Journal of Public Health 1998;88:216-222. [PubMed: 9491010]

Duncan SC, Strycker LA, Duncan TE. Exploring associations in developmental trends of adolescent substance use and risky sexual behavior in a high-risk population. Journal of Behavioral Medicine 1999;22:21-34. [PubMed: 10196727]

Duncan SC, Duncan TE, Strycker LA. A multilevel analysis of neighborhood context and youth alcohol and drug problems. Prevention Science 2002;3:125-133. [PubMed: 12088137]

Dunlap E, Johnson BD. The setting for the crack era: macro forces, micro consequences (1960-1992). J. Psychoactive Drugs 1992;24:307-321. [PubMed: 1491281]

DuRant RH, Kahn J, Beckford PH, Woods ER. The association of weapon carrying and fighting on school property and other health risk and problem behaviors among high school students. Arch. Pediatr. Adolesc.Med 1997;151:360-366. [PubMed: 9111434]

Ellickson PL, Tucker JS, Klein DJ. Ten-year prospective study of public health problems associated with early drinking. Pediatrics 2003;111:949-955. [PubMed: 12728070] 
Ennett ST, Flewelling RL, Lindrooth RC, Norton EC. School and neighborhood characteristics associated with school rates of alcohol, cigarette and marijuana use. Journal of Health and Social Behavior 1997;38:55-71. [PubMed: 9097508]

Ensminger ME, Lamkin RP, Jacobson N. School leaving: a longitudinal perspective including neighborhood effects. Child Development 1996;67:2400-2416. [PubMed: 9022247]

Grant BF, Stinson FS, Harford TC. Age at onset of alcohol use and DSM-IV alcohol abuse and dependence: A 12-year follow-up. Journal of Substance Abuse 2001;13:493-504. [PubMed: 11775078]

Graves KL, Leigh BC. The relationship of substance use to sexual-activity among young-adults in the United-States. Family Planning Perspectives 1995;27:18-22. [PubMed: 7720848]

Greene MH, DuPont RL. The epidemiology of drug abuse. Foreward. Am.J Public Health 1974;64 (Suppl):iii-iiv. [PubMed: 4429169]

Groves RM. Non-response rates and non-response bias in household surveys. Public Opinion Quarterly 2006;70(5):646-675.

Grube JW. Preventing sales of alcohol to minors: results from a community trial. Addiction 1997;92 (Suppl 2):S251-S260. [PubMed: 9231448]

Gruenewald PJ, Johnson FW. The stability and reliability of self-reported drinking measures. Journal of Studies on Alcohol 2006;67:738-745. [PubMed: 16847543]

Grunbaum JA, Basen-Engquist K, Pandey D. Association between violent behaviors and substance use among Mexican-American and non-Hispanic white high school students. J Adolesc.Health 1998;23:153-159. [PubMed: 9730358]

Hingson R, McGovern T, Howland J, Heeren T, Winter M, Zakocs R. Reducing alcohol-impaired driving in Massachusetts: the Saving Lives Program. Am. J. Public Health 1996;86:791-797. [PubMed: 8659651]

Hochschild, AR. The time bind: When work becomes home and home becomes work. Henry Holt; New York: 1997.

Holder HD, Saltz RF, Grube JW, Treno AJ, Reynolds RI, Voas RB, Gruenewald PJ. Summing up: lessons from a comprehensive community prevention trial. Addiction 1997;92(Suppl 2):S293-S301. [PubMed: 9231452]

Hughes PH, Crawford GA, Barker NW, Schumann S, Jaffe JH. The social structure of a heroin copping community. Am. J. Psychiatry 1971;128:551-558. [PubMed: 5114369]

Jencks, C.; Mayer, SE. The social consequences of growing up in a poor neighborhood. In: Lynn, LE.; McGeary, MGH., editors. Inner-city poverty in the United States. National Academy Press; Washington, DC: 1990. p. 111-186.

Johnston, LD.; O'Malley, PM.; Bachman, JG.; Schulenberg, JE. Monitoring the Future national results on adolescent drug use: Overview of key findings, 2007. National Institute on Drug Abuse; Bethesda, MD: 2008. NIH Publication No. 08-6418

Kandel D, Yamaguchi K. From beer to crack: developmental patterns of drug involvement. Am. J. Public Health 1993;83:851-855. [PubMed: 8498623]

Kandel DB, Yamaguchi K. Job mobility and drug-use - an event history analysis. American Journal of Sociology 1987;92:836-878.

Kandel, DB.; Davies, M. Progression to regular marijuana involvement: Phenomenology and risk factors for near-daily use. Glantz, M.; Pickens, R., editors. American Psychological Association; Washington, DC: 1992. p. 211-253.

Kandel DB, Schaffran C, Griesler PC, Hu MC, Davies M, Benowitz N. Salivary cotinine concentration versus self-reported cigarette smoking: three patterns of inconsistency in adolescence. Nicotine and Tobacco Research 2006;8:525-537. [PubMed: 16920650]

Karvonen S, Rimpela AH. Urban small area variation in adolescent health behavior. Social Science and Medicine 1997;45:1089-1098. [PubMed: 9257400]

Katz J, Carey VJ, Zeger SL, Sommer A. Estimation of design effects and diarrhea clustering within households and villages. Am. J. Epidemiol 1993;138:994-1006. [PubMed: 8256785]

Keeter S, Kennedy C, Dimock M, Best J, Craighill P. Gauging the impact of growing nonresponse on estimates from a national RDD telephone survey. Public Opinion Quarterly 2006;70(5):759-779. 
Keeter S, Miller C, Kohut A, Groves RM, Presser S. consequences of reducing nonresponse in a large national telephone survey. Public Opinion Quarterly 2000;64(2):125-148. [PubMed: 10984330]

Kreiter SR, Krowchuk DP, Woods CR, Sinal SH, Lawless MR, DuRant RH. Gender differences in risk behaviors among adolescents who experience date fighting. Pediatrics 1999;104:1286-1292. [PubMed: 10585979]

Lambert SF, Brown TL, Phillips CM, Ialongo NS. The relationship between perceptions of neighborhood characteristics and substance use among urban African American adolescent. American Journal of Community Psychology 2004;34:205-218. [PubMed: 15663207]

Leigh BC, Schafer J, Temple MT. Alcohol use and contraception in first sexual experiences. J. Behav. Med 1995;18:81-95. [PubMed: 7595954]

Leventhal T, Brooks-Gunn J. The neighborhoods they live in: the effects of neighborhood residence on child and adolescent outcomes. Psychological Bulletin 2000;126:309-337. [PubMed: 10748645]

Luthar SS, D'Avanzo K. Contextual factors in substance abuse: a study of suburban and inner-city adolescents. Development and Psychology 1999;11:845-867.

Luthar SS, Becker BE. Privileged but pressured? A study of affluent youth. Child Development 2002;73:1593-1610. [PubMed: 12361321]

Massey DS. The age of extremes: Concentrated affluence and poverty in the twenty-first century. Demography 1996;33:395-412. [PubMed: 8939412]

Mayer SE, Jencks C. Growing Up in Poor Neighborhoods - How Much Does It Matter. Science 1989;243:1441-1445. [PubMed: 17839748]

Midanik L. Self-report alcohol consumption and alcohol problems: a literature review. British Journal of Addiction 1982;77:357-382. [PubMed: 6762224]

Montgomery JM, Foley KL, Wolfson M. Enforcing the minimum drinking age: state, local and agency characteristics associated with compliance checks and Cops in Shops programs. Addiction 2006;101:223-231. [PubMed: 16445551]

Morris, JN. Uses of Epidemiology. 3rd ed.. Churchill Livingstone; New York, NY: 1975.

Mulhall PF, Stone D, Stone B. Home alone: Is it a risk factor for middle school youth and drug use? Journal of Drug Education 1996;26:39-48. [PubMed: 8991968]

National Research Council and Institute of Medicine. Reducing Underage Drinking -- A Collective Responsibility. National Academies Press; Washington, DC: 2004.

O'Brien MC, McCoy TP, Champion H, Mitra A, Robbins A, Teuschlser H, Wolfson M, DuRant RH. Single question about drunkenness to detect college students risk for injury. Acad. Emerg. Med 2006;13:629-636. [PubMed: 16614453]

Office of Juvenile Justice and Delinquency Prevention (OJJDP). Enforcing the Underage Drinking Laws (EUDL) Discretionary Program: Community Trials Initiative. Fiscal Year 2003 Solicitation; Washington, DC: 2003.

Perry CL, Williams CL, Veblen-Mortenson S, Toomey TL, Komro KA, Anstine PS, et al. Project Northland: outcomes of a communitywide alcohol use prevention program during early adolescence. Am. J. Public Health 1996;86:956-965. [PubMed: 8669519]

Petronis KR, Anthony JC. Perceived risk of cocaine use and experience with cocaine: do they cluster within US neighborhoods and cities? Drug Alcohol Depend 2000;57:183-192. [PubMed: 10661669]

Petronis KR, Anthony JC. A different kind of contextual effect: geographical clustering of cocaine incidence in the USA. Journal of Epidemiology and Community Health 2003;57:893-900. [PubMed: 14600117]

Preisser JS, Arcury TA, Quandt SA. Detecting patterns of occupational illness clustering with alternating logistic regressions applied to longitudinal data. Am. J. Epidemiol 2003;158:495-501. [PubMed: 12936905]

Reboussin BA, Song EY, Shrestha A, Lohman KK, Wolfson M. A latent class analysis of underage problem drinking: Evidence from a community sample of 16-20 year olds. Drug Alcohol Depend 2005;83:199-209. [PubMed: 16359829]

Richardson JL, Radziszewska B, Dent CW, Flay BR. Relationship between after-school care of adolescents and substance use, risk taking, depressed mood, and academic achievement. Pediatrics 1993;23:32-38. [PubMed: 8516082] 
Robins LN, Przybeck TR. Age of onset of drug use as a factor in drug and other disorders. NIDA Res.Monogr 1985;56:178-192. [PubMed: 3929100]

Song EY, Reboussin BA, Foley KL, Kaltenbach LA, Wagoner K, Wolfson M. Selected community characteristics and underage drinking. Substance Use and Misus 2009;44:179-194.

Steinhausen H, Metzke CW. Frequency and correlates of substance use among preadolescents and adolescents in a Swiss epidemiological study. Journal of Child Psychology and Psychiatry and Allied Disciplines 1998;39:387-397.

Substance Abuse and Mental Health Services Adminstration (SAMHSA). Results from the 2005 National Survey on Drug Use and Health: National Findings. SAMHSA, Office of Applied Studies; Rockville, MD: 2006. NSDUH Series H-30, DHHS Pub. No. SMA 06-4194

Swahn MH, Simon TR, Hammig BJ, Guerrero JL. Alcohol-consumption behaviors and risk for physical fighting and injuries among adolescent drinkers. Addict. Behav 2004;29:959-963. [PubMed: 15219342]

Trim RS, Chassin L. Neighborhood socioeconomic status effects on adolescent alcohol outcomes using growth models: exploring the role of parental alcoholism. J. Stud. Alcohol Drugs 2008;69:639-648. [PubMed: 18781238]

Wagenaar AC, Komro KA, McGovern P, Williams CL, Perry CL. Effects of a saliva test pipeline procedure on adolescent self-report alcohol use. Addiction 1993;88:199-208. [PubMed: 8220058]

Wagenaar AC, Murray DM, Gehan JP, Wolfson M, Forster JL, Toomey TL, Perry CL, Jones-Webb R. Communities mobilizing for change on alcohol: outcomes from a randomized community trial. J. Stud. Alcohol 2000;61:85-94. [PubMed: 10627101]

Wagner FA, Anthony JC. From first drug use to drug dependence; developmental periods of risk for dependence upon marijuana, cocaine, and alcohol. Neuropsychopharmacology 2002;26:479-488. [PubMed: 11927172]

Wells JE, Degenhardt L, Bohnert KM, Anthony JC, Scott KM, for the New Zealand Mental Health Survey Research Team. Geographical clustering of cannabis use: Results from the New Zealand Mental Health Survey 2003-2004. Drug Alcohol Depend 2008;99:309-316. [PubMed: 18990513]

White HR, Loeber R, Stouthamer-Loeber M, Farrington DP. Developmental associations between substance use and violence. Developmental Psychopathology 1999;11:785-803.

Wilson, WJ. The world of the new urban poor. Alfred A. Knopf; New York: 1996. When work disappears.

Wilson N, Syme SL, Boyce WT, Battistich VA, Selvin S. Adolescent alcohol, tobacco, and marijuana use: the influence of neighborhood disorder and hope. Am. J. Health Promot 2005;20:11-19. [PubMed: 16171156]

Wolfson, M.; Song, E.; Martin, B.; Wagoner, K.; Brown, V.; Suerken, C.; Reboussin, B.; Foley, K.; Preisser, J.; Garner, G.; Hulme, S.; Miller, C. National evaluation of the Enforcing Underage Drinking Laws Randomized Community Trial: Year 1 Report. Wake Forest University School of Medicine; Winston-Salem, NC: 2005. 
Table 1

Community-level variables and definitions: 2000 US Census City/Town Level Data

\begin{tabular}{|l|l|}
\hline Variables & Census Definitions \\
\hline Neighborhood Disadvantage & Median household income (\$) \\
Median household income & Below poverty level (\%) \\
Poverty & Bachelor's degree or higher (\%) \\
College Education & Employed civilian population 16 years and over (\%) \\
Employment & Renter-occupied housing units (\%) \\
Housing tenure & \\
\hline Neighborhood disorder & Vacant housing units (\%) \\
Vacant housing units & Number of violent crimes divided by population \\
Crime & Housing density per square mile of land area \\
Housing density & Total population \\
Population size & Lived in a different county in the US in 1995 (\%) \\
Mobility & \\
\hline Family Structure & \\
Married-couple family & Married couple family (\%) \\
Grandparents as caregivers & Grandparents responsible for grandchildren (\%) \\
Female head of household & Female householder, no husband present $(\%)$ \\
\hline Racial Composition & \\
White & Caucasian $(\%)$ \\
Foreign Born & Foreign born (\%) \\
\hline
\end{tabular}


Table 2

Basic $2 \times 2$ table for estimation of a pairwise odds ratio (PWOR) without covariates using alternating logistic regression (ALR)

\begin{tabular}{|c|c|c|}
\hline & \multicolumn{2}{|c|}{ 2nd Youth in the Pair } \\
\hline $\mathbf{1}^{\text {st }}$ Youth in the Pair & Yes & No \\
\hline Yes & $\mathrm{a}$ & $\mathrm{b} / 2$ \\
\hline No & $\mathrm{b} / 2$ & $\mathrm{c}$ \\
\hline
\end{tabular}




\section{Table 3}

Clustering of underage drinking behaviors within communities as estimated by alternating logistic regression (ALR) with and without adjustment for individual-level covariates $(\mathrm{N}=18,730)$.

\begin{tabular}{lcc}
\hline & Unadjusted PWOR $\mathbf{l}^{\mathbf{9 5} \% \mathbf{C I})}$ & ${\left.\text { Adjusted } \text { PWOR }^{\mathbf{2}} \mathbf{( 9 5 \%} \mathbf{~ C I}\right)}$ \\
\hline Past 30 day drinking & $1.08(1.04,1.11)$ & $1.10(1.06,1.14)$ \\
Heavy episodic or binge drinking & $1.08(1.04,1.12)$ & $1.08(1.04,1.12)$ \\
Drunkenness & $1.08(1.05,1.12)$ & $1.09(1.05,1.14)$ \\
Non-violent consequences & $1.05(1.03,1.07)$ & $1.06(1.03,1.08)$ \\
Purchase attempt & $1.21(1.12,1.30)$ & $1.27(1.15,1.40)$ \\
\hline &
\end{tabular}




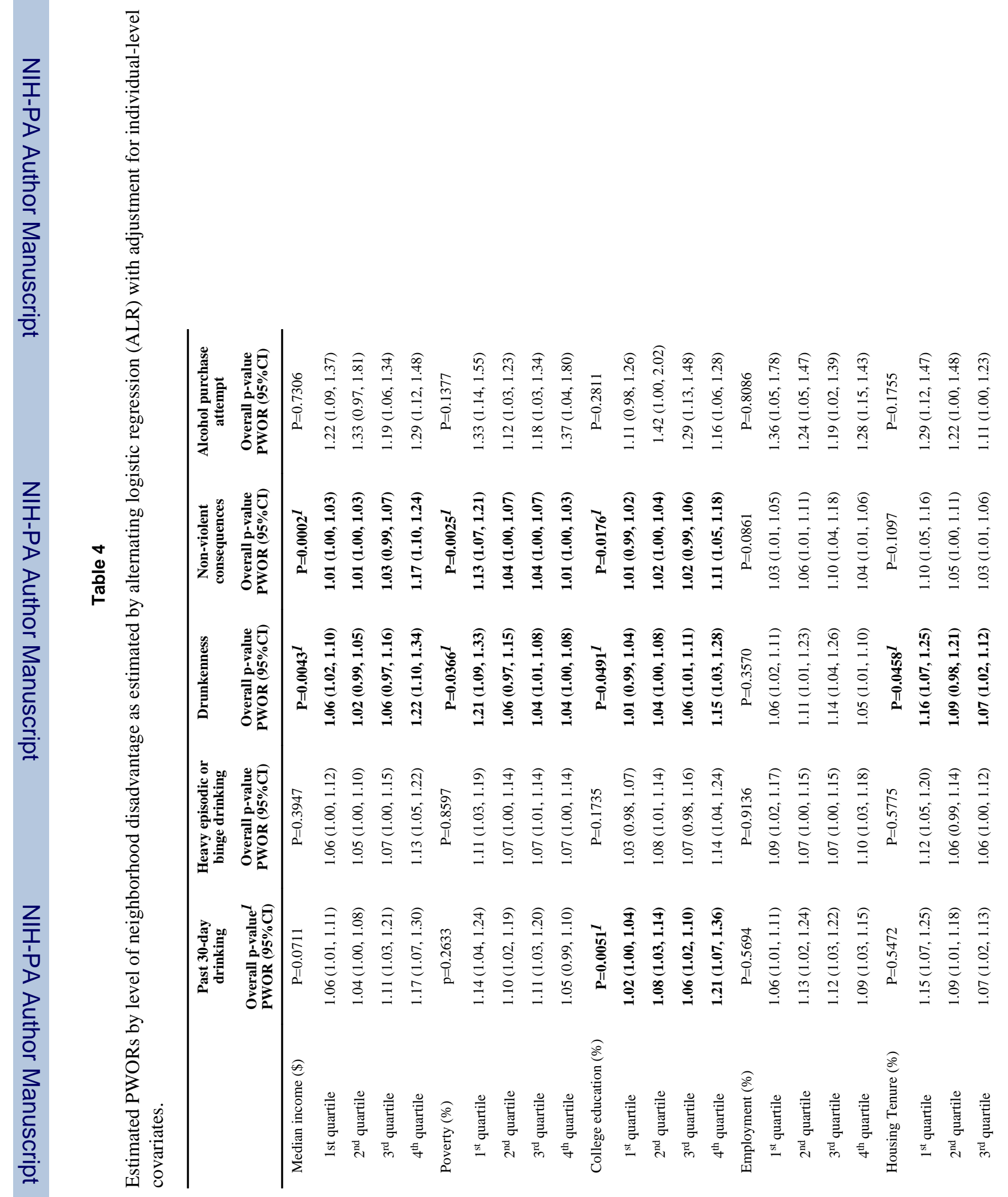




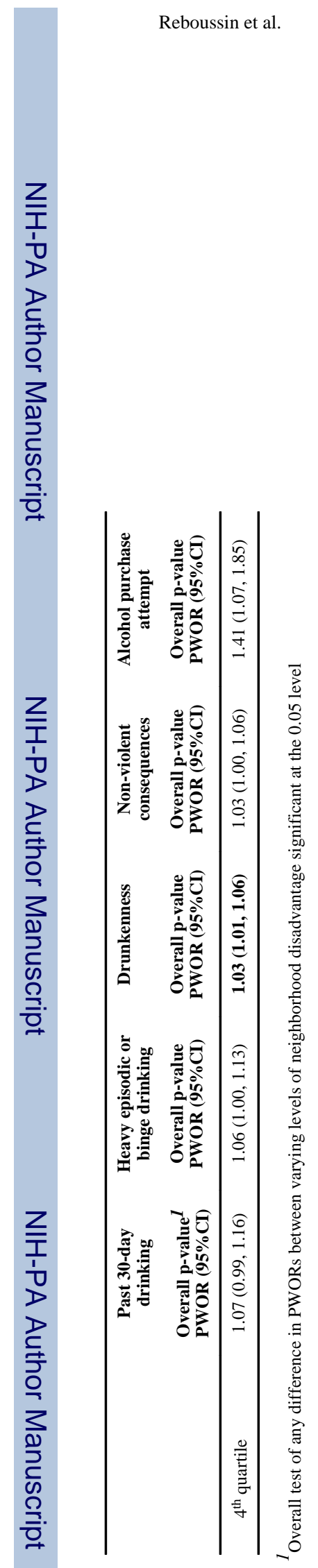

Drug Alcohol Depend. Author manuscript; available in PMC 2011 January 1. 


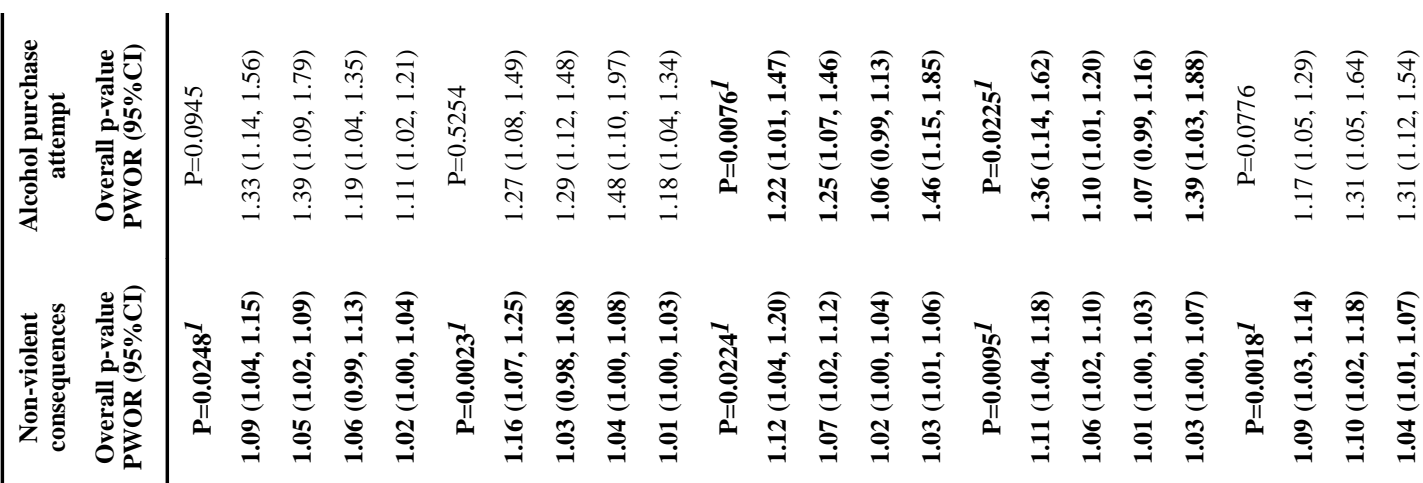

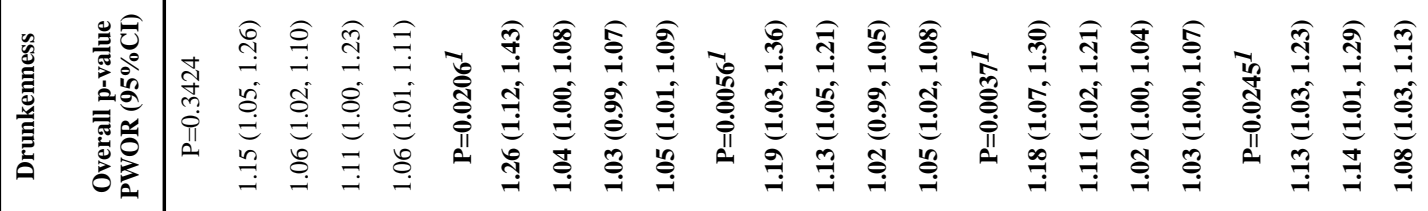

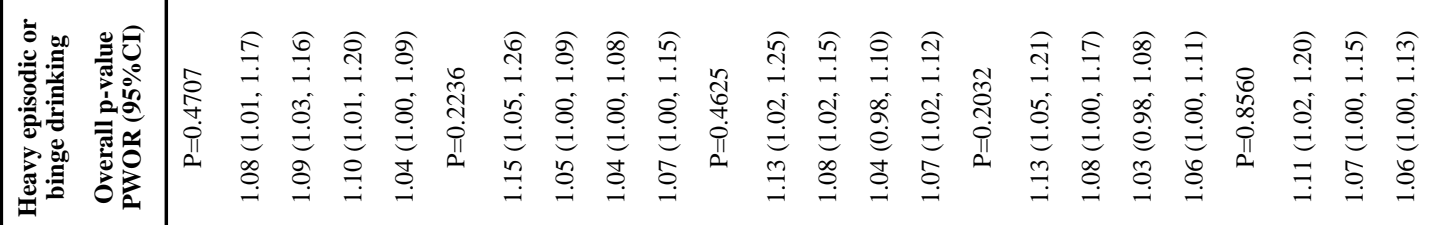

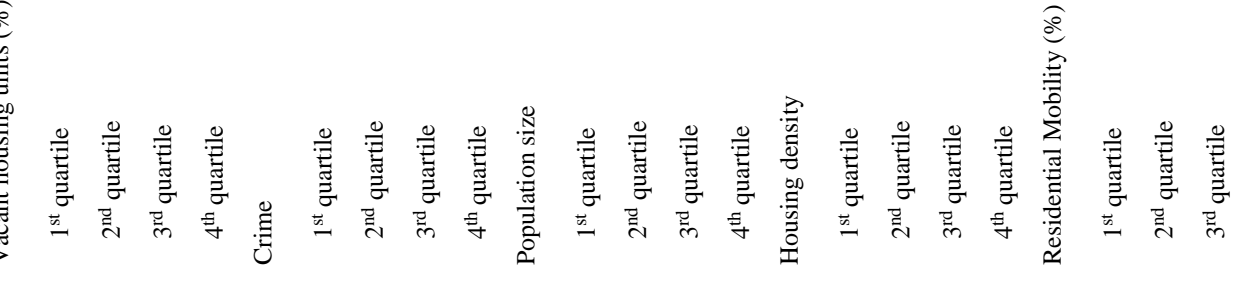




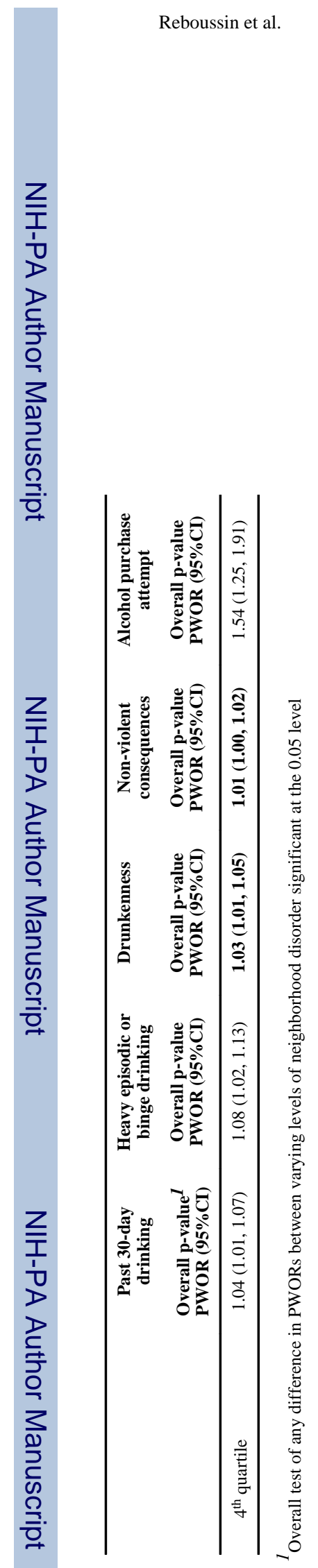

Drug Alcohol Depend. Author manuscript; available in PMC 2011 January 1. 


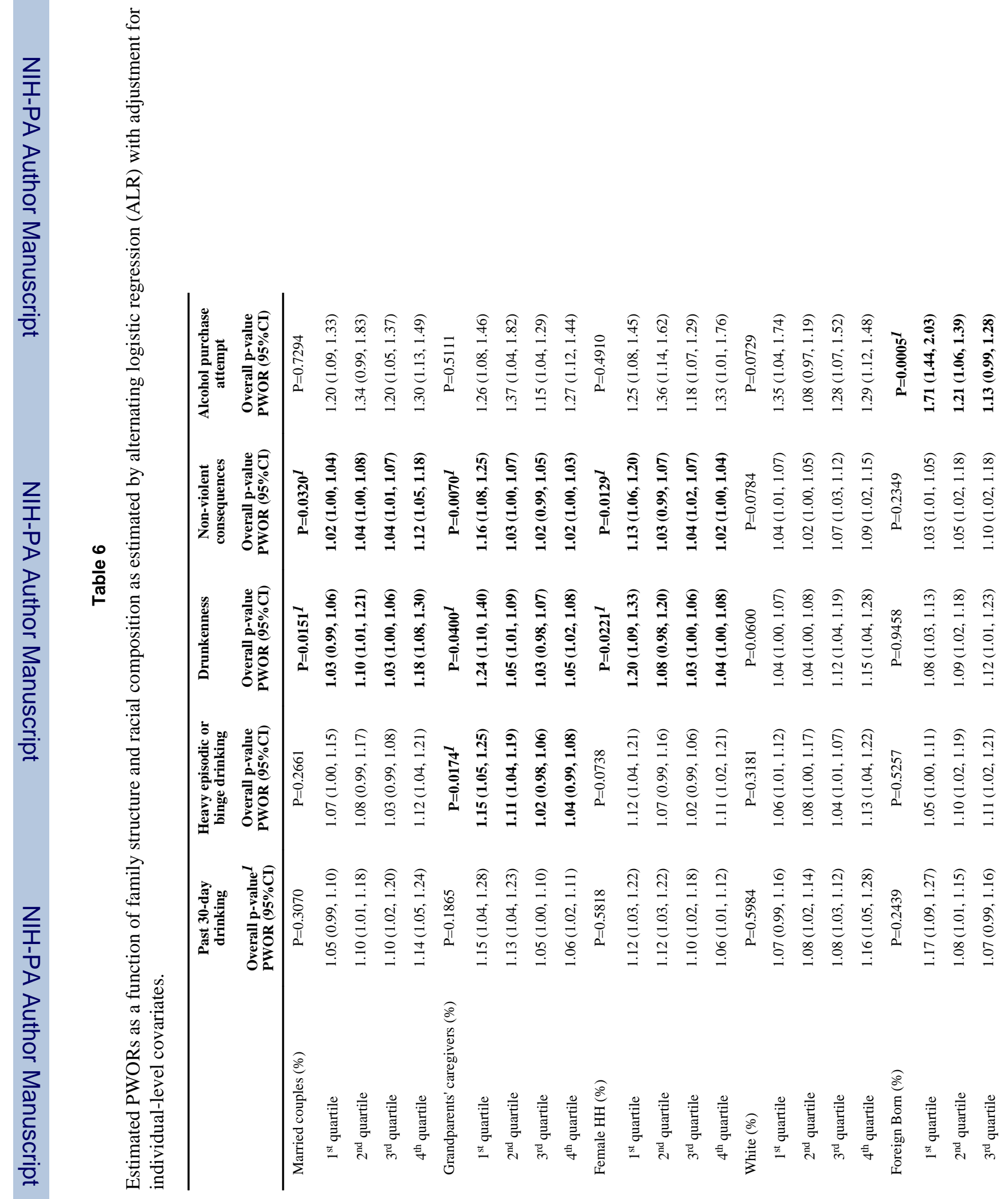




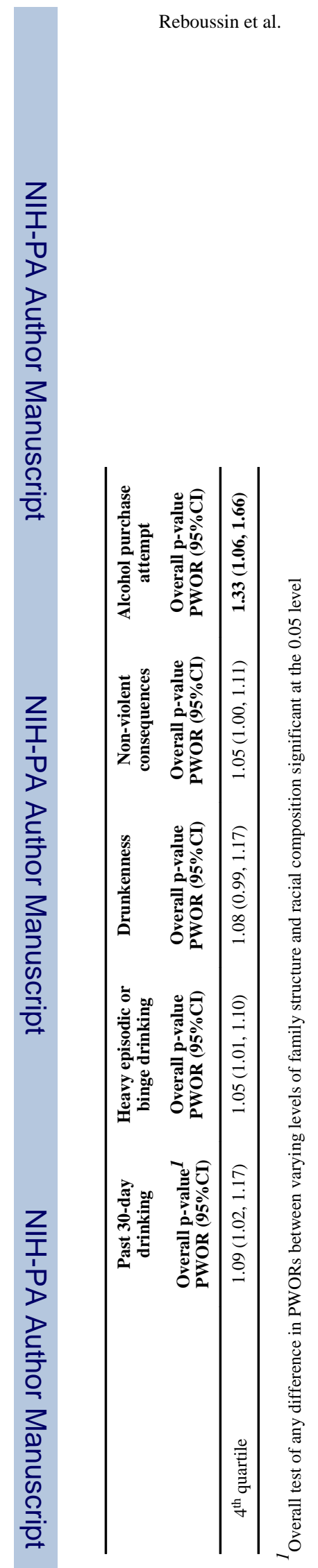

Drug Alcohol Depend. Author manuscript; available in PMC 2011 January 1. 